\title{
Determination of Postmortem Interval by Estimating CSF Proteins Concentration after Death, by Dye Binding Method at a Tertiary Care Hospital in Lahore, Pakistan
}

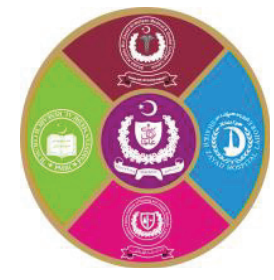

${ }^{1}$ Arooj Farooq, ${ }^{2}$ Aatiqa Abbas, ${ }^{2}$ Arif Rasheed

${ }^{1}$ Department of Forensic Medicine, Nawaz Sharif Medical College, Gujrat

${ }^{2}$ Department of Forensic Medicine, King Edward Medical University, Lahore

\begin{abstract}
Introduction: Postmortem interval (PMI) is the time lapse between death of a person and its postmortem examination i.e. autopsy. Estimating the postmortem interval (PMI) is an imperative perspective of forensic medicine.

Aims \& Objectives: This study was conducted to see the impact of CSF protein estimation on determination of PMI.

Place and duration of study: It was an observational correlational study, conducted for one year at Department of Forensic Medicine, King Edward Medical University Lahore.

Material \& Methods: A total of 119 cadavers were included in this study. Chemicals used were disodium molybdate, pyrogallol, succinic acid. The minimum detectable concentration of total proteins in CSF with dye binding method using pyrogallol red was determined as $0.022 \mathrm{~g} / \mathrm{l}$. Two $\mathrm{ml}$ of CSF was taken from each cadaver. Clear, colorless samples were taken in test tubes. Turbid and blood contained samples were not included in study. Protein concentration was determined using photospectrometry. Statistical analysis was done by SPSS-23. Quantitative variables like age were presented as mean $\pm \mathrm{SD}$. Qualitative variables like gender were presented as frequency and percentages. For comparison between PMI and CSF proteins concentration correlation was applied.

Results: Males accounted for majority of our subjects. The mean value of proteins in CSF was $219.91 \pm 113.121 \mathrm{mg} / \mathrm{dl}$. The most common PMI was 11 to 20 hours. CSF proteins increased gradually over 72 hours after death. The results of present study showed a significant positive correlation between time of death and CSF proteins concentration after death. Conclusion: It is observed that as a whole protein concentration increased with increasing time of death. Hence, CSF protein concentration can be used in estimating time since death.
\end{abstract}

Key words: Postmortem interval (PMI), Cerebrospinal fluid, protein concentration.

\section{INTRODUCTION}

$\mathrm{P}$ ostmortem interval (PMI) is the time lapse between death of a person and its postmortem examination i.e. autopsy. ${ }^{1}$ Estimating the postmortem interval (PMI) is an imperative perspective of forensic medicine. ${ }^{2}$ Time elapsed since death gives numerous significant advantages to concerned investigating officials of both victim and assailant. ${ }^{3}$ PMI can support beholders claim, corroborate the potential in provided proof, help in implementing given news in making further decisions, and serve as an evidence for further actions. ${ }^{4}$ In known cases, information about time since death can be obtained from relatives or police officials but in unknown cases this information cannot be obtained. ${ }^{5}$ Such cases, require special attention and proper methods for measuring PMI so that investigations can progress in a prudent and prompt way.
After death, the body undergoes significant changes in its physical, histological and chemical composition which are pivotal tools for determining time since death. ${ }^{6}$ These transformations lead to estimation of PMI. ${ }^{7}$ Precise and careful association of these variations should be established with time since death. Physical methods are used for estimating PMI. ${ }^{8}$ After death, initially some changes take place, for example, temperature regulation i.e. balance of temperature of dead body and environment called Algor mortis. In the same way stiffening of muscles of body after death called rigor mortis, and skin color changes called livor mortis, all provide valuable clues and were under practice. Decomposition is the result of autolysis which is tissue breakdown by body's own enzymes and putrefaction which is result of bacterial involvement. Disintegration in tissue morphology, putrefaction and adipocere formation are different types of body decomposition. These processes occur at different intervals. ${ }^{9}$ 
No doubt, these methods depict changes and these changes are correlated with PMI, but multiple researches have shown that these physical changes get influenced by climatic changes, age of deceased, and any underlying disease. ${ }^{10}$

Therefore, lack of precision of physical methods led to introduction of biochemical methods. ${ }^{11}$ These biochemical methods are based on systemic pathophysiological changes and are found to be more precise as the involvement of external conditions is less. ${ }^{12}$ Body fluids like blood, CSF, synovial fluid and vitreous humor undergo changes in their biochemistry after death. These changes are due to breakdown of cells and effusion of discharge or waste products from cells. It means these biochemical markers can give information about changing metabolic environment of the deceased. Furthermore, their use for determination of PMI can alleviate bias or human error present in above mentioned methods, making biochemical method are more sensitive. ${ }^{13}$

CSF is a body fluid present in Central Nervous System around brain and spinal cord which has no specific colour and odour. CSF is produced from specific cellular system in the ventricular system of brain called ependymal cells in choroid plexus. ${ }^{14}$ Once it is formed it is circulated around brain and spinal cord and then reabsorbed by arachnoid granulations. CSF is an ultra-filtrate of plasma hence it has small percentage of proteins and small quantity of blood cells which are mainly WBCs. In electrolyte concentration, sodium ions are equal in proportion as in plasma and chloride and magnesium ions are in a bit larger concentration. ${ }^{15}$ Quantity of CSF is almost $150 \mathrm{ml}$ in which $0.3 \%$ or $15-45 \mathrm{mg} / \mathrm{dl}$ are proteins or even lower in case of children. Protein concentration in CSF also depends on site from where the sample has been taken. Normally protein concentration is lower in cisternal and ventricular areas but a bit higher in lumbar region. ${ }^{16}$

In a healthy person, the balance between brain and blood fluids is maintained by Blood Brain Barrier which is composed of highly sensitive and specific cells for maintaining influx and efflux into brain. If due to any reason, cellular or protein content of CSF exceeds above normal, it may indicate some underlying brain disease. This point can be utilized even after death that if concentration of proteins changes it can be correlated with determination of PMI. ${ }^{17}$

\section{MATERIAL AND METHODS}

It was an observational co-relational study, conducted at the Department of Forensic Medicine and Toxicology in collaboration with Department of Chemical Pathology, KEMU, Lahore. The study was approved by the institutional review board of KEMU, Lahore vide letter No 311/RC/KEMU dated 05-12-2019. The study was conducted for a period of one year (February 2018-Feburary 2019). Sample size of 119 patients was estimated by using 95\% Confidence level, 6\% Absolute Precision with expected Percentage change in proteins $87.3 \%$.

Non probability consecutive sampling method was used and every dead body presenting in forensic medicine department KEMU, Lahore with known time since death up to 72 hours was included. The time of death was verified as per police records. Bodies with incomplete records or time of death greater than 72 hours were excluded.

Disodium molybdate, pyrogallol and succinic acid were used. The minimum detectable concentration of total proteins in CSF with dye binding method using pyrogallol red was determined as $0.022 \mathrm{~g} / \mathrm{l}$. Semi auto biochemical analyzer was used which worked on the principle of spectrophotometry. Quantitative values of proteins were obtained automatically through auto biochemical analyzer. CSF sample was collected by lumber puncture from space between L3-L4 or L4-L5. Lumbar puncture needle of 20 gauge was used for this purpose. Two $\mathrm{ml}$ of CSF was taken from each cadaver. Clear, colorless samples were taken in test tubes. Turbid and blood contained samples were not included in study.

\section{Statistical analysis:}

Statistical analysis was done by SPSS-23. Quantitative variables like age were presented as mean $\pm \mathrm{SD}$. Qualitative variables like gender were presented as frequency and percentages. For comparison between PMI and CSF proteins concentration correlation was applied.

\section{RESULTS}

\begin{tabular}{|c|c|c|}
\hline Gender & Frequency & Percentage \% \\
\hline Male & 90 & $75.6 \%$ \\
\hline Female & 29 & $24.4 \%$ \\
\hline Total & 119 & $100 \%$ \\
\hline
\end{tabular}

Table-1: Gender distribution of study subjects

It is evident from Table-1, total number of cases in this study were 119 , out of which 90 were males $(75.6 \%)$ and $29(24.4 \%)$ were female cases. It is obvious that proportion of males exceeded proportion of females in current study. 


\begin{tabular}{|l|l|}
\hline Variable & Mean \pm SD \\
\hline CSF PROTEINS mg/dl & $219.91 \pm 113.121$ \\
PMI in hours & $033.40 \pm 021.997$ \\
\hline
\end{tabular}

Table-2: Descriptive analysis of PMI and CSF proteins

Table-2 exhibits that the Mean \pm SD of proteins in CSF and PMI in current study.

\begin{tabular}{|l|c|c|}
\hline Time in Hours & Frequency & Percentage\% \\
\hline Hours less than 11 & 20 & $16.8 \%$ \\
\hline Between 11 to 20 & 26 & $21.8 \%$ \\
\hline Between 21 to 30 & 16 & $13.4 \%$ \\
\hline Between 31 to 40 & 14 & $11.8 \%$ \\
\hline Between 41 to 50 & 13 & $10.9 \%$ \\
\hline Between 51 to 60 & 7 & $5.9 \%$ \\
\hline Between 61 and 72 & 23 & $19.3 \%$ \\
\hline Total & 119 & 100.0 \\
\hline
\end{tabular}

Table-3: PMI groups and frequency of cases

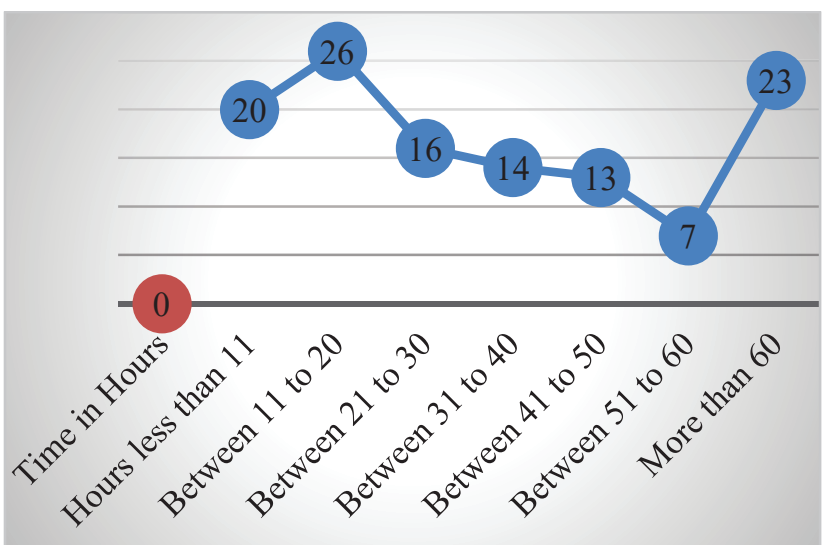

Fig-1: Frequency of cases with increasing PMI

As evident in Table-3 and Fig-1, From total 119 samples of CSF, maximum number of samples falls in the time period of 11 to 20 hours, i.e. $26(21.8 \%)$, followed by time period of more than 60 hours i.e. $23(19.3 \%)$. The minimum number of samples falls within the time period of 51-60 hours i.e. $7(5.9 \%)$ as shown in Table-3.

\begin{tabular}{|l|c|l|}
\hline Timings & Frequency & Mean \pm SD \\
\hline Hours less than 11 & 20 & $81.65 \pm 17.685$ \\
\hline Between 11 to 20 & 26 & $138.27 \pm 12.957$ \\
\hline Between 21 to 30 & 16 & $170.00 \pm 11.419$ \\
\hline Between 31 to 40 & 14 & $224.64 \pm 18.492$ \\
\hline Between 41 to 50 & 13 & $275.15 \pm 13.619$ \\
\hline Between 51 to 60 & 7 & $324.57 \pm 13.974$ \\
\hline Between 61 to 72 & 23 & $401.17 \pm 31.767$ \\
\hline All & 119 & $219.91 \pm 113.121$ \\
\hline
\end{tabular}

Table-4: CSF proteins (mg/dl) in cadavers with increasing PMI

From Table-4, it is observed that concentration of total proteins in CSF in deceased persons is increasing with increasing time interval upto 72 hours. In first 10 hours, CSF proteins concentration was $81 \pm 17 \mathrm{mg} / \mathrm{dl}$ and increase of $57 \mathrm{mg} / \mathrm{dl}$ was observed in next 10 hours. In subsequent groups of 10 hours each $32 \mathrm{mg} / \mathrm{dl}, 54 \mathrm{mg} / \mathrm{dl}, 51 \mathrm{mg} / \mathrm{dl}$, $49 \mathrm{mg} / \mathrm{dl}, 77 \mathrm{mg} / \mathrm{dl}$ increase of CSF proteins was observed respectively.

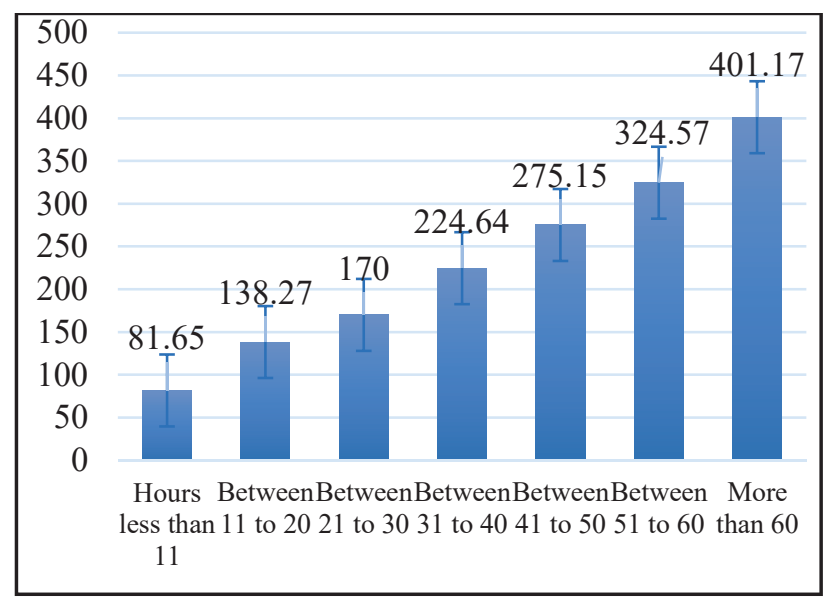

Fig-2: Concentration of proteins with increasing PMI

It is obvious from Fig-2 that concentration of proteins is increasing with increasing postmortem interval.

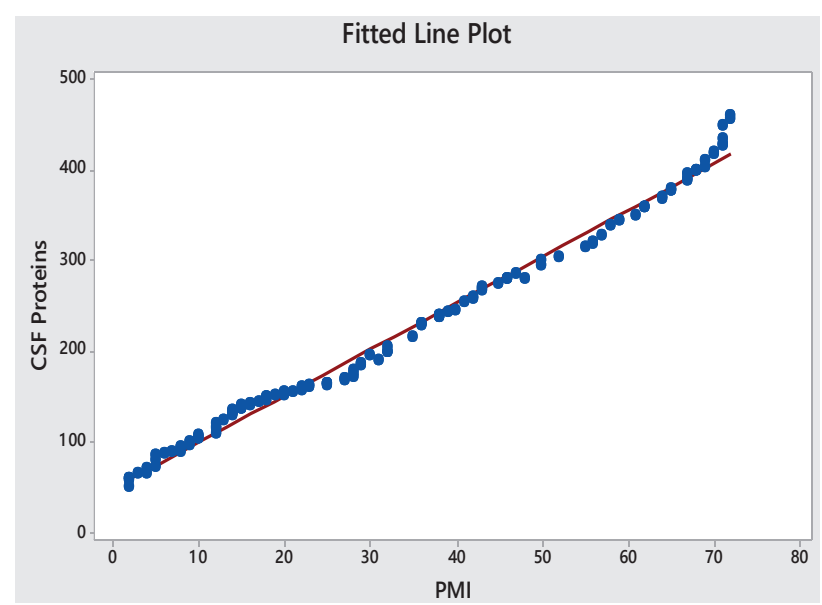

Fig-3: Scatterplot between PMI and CSF proteins

It is clear from the above scatter plot that with increasing postmortem interval quantity of proteins in CSF of cadavers tends to rise. So, there is a linear relation between PMI and CSF Proteins concentration.

\begin{tabular}{|l|c|c|c|}
\hline Variable & $\begin{array}{c}\text { Regression } \\
\text { Coefficient }\end{array}$ & t-statistic & P-value \\
\hline Constant & -9.158 & -21.316 & .001 \\
\hline $\begin{array}{l}\text { CSF proteins } \\
\mathrm{mg} / \mathrm{dl} .\end{array}$ & 0.1935 & 111.311 & .001 \\
\hline
\end{tabular}

Table-5: Regression model of PMI on CSF protein 
The linear regression equation is:

PMI $(\mathrm{Y})=-9.158+0.1935(\mathrm{X})$ CSF Proteins

The results of present study showed a significant positive correlation between time of death and CSF proteins concentration after death (Table-5).

\begin{tabular}{|c|c|c|c|}
\hline Case No & Actual Time & Predicted Time & Error \\
\hline 4 & 2 & 2.45 & -0.45 \\
\hline 17 & 9 & 10.19 & -1.19 \\
\hline 72 & 65 & 64.37 & 0.63 \\
\hline
\end{tabular}

Table-6: In sample testing

Tabulated form representing sample testing, in which random samples were chosen and then entered in equation of regression model and we obtained the above values.

It was observed in case no 4 , that actual time in hours estimated from circumstantial evidence was 2 hrs, and after applying values in regression equation, predicted time was 2.45 with an error of 0.45 hrs. Similarly, in case no 17 actual time was 9 hrs and predicted time was $10.19 \mathrm{hrs}$ with an error of 1.19 . In the same way, in case 72 , actual time was $65 \mathrm{hrs}$ and predicted time was 64.37 with an error of 0.63 (Table-6).

\section{Accuracy of Model:}

From the regression model, $\mathrm{R}^{2}=99.1 \%$.

\section{DISCUSSION}

Determination of time since death is an inevitable demand now a days. Various studies have been conducted and numerous methods have been introduced and applied for this purpose. In the present study, CSF samples from dead bodies of known time since death (taken from circumstantial evidence i.e. relatives and police) were obtained from lumbar puncture at the level of L3-L4 and L4 L5 and analyzed for concentration of total proteins in CSF via dye binding method using calorimetric technique. CSF samples were collected from dead bodies within 72 hours after death.

In the present study, out of 119 dead bodies 90 were males and 29 were females with a male to female ratio of $3: 1$ as shown in table 4 . Whereas sample size of research work of, Parmar and Menon $(2015)^{18}$ and Morikawa et al $(2016)^{19}$ is 100 and 189 respectively with a bit different male to female ratio of 2.5:1, 1.1: 1 and 2.5: 1 respectively. This difference might be the result of difference in sample size.

CSF samples were taken from lumber region in the present study whereas the earlier researchers ${ }^{15-19}$ have studied CSF biochemistry on cisternal fluid aspirates. Cisternal fluid aspiration is a blind procedure, and it becomes difficult in obese bodies with increased subcutaneous fat around neck and when the body is in full rigor. ${ }^{13}$ CSF protein concentration is lowest in the ventricular CSF, intermediate in the Cisterna magna, and highest in the lumbar region. The difference between the cisterna magna and lumbar region is of order $0.1 \mathrm{~g} / \mathrm{l}^{12}$

Current study revealed that total CSF proteins concentration increased up till 72 hours.

In current study, concentration of total proteins in CSF has been estimated to correlate it with PMI, as it is present in a closed cavity and resists the effects of putrefaction. It was observed that concentration of total proteins increased as the time since death increases. Post mortem time period was divided into 7 groups of 10 hours each so that serial rise in proteins can be observed. It was observed that there was a uniform increase in proteins concentration throughout the defined duration i.e. 72 hours (Fig-4). The linear regression equation in current study derived by using current study data came out to be:

PMI $=-9.158+0.1935$ CSF Proteins

Coefficient of determination ( $\mathrm{R}$ squared) $\mathrm{R}^{2}=99.1 \%$

The results of present study showed a significant positive correlation between time of death and CSF proteins concentration after death.

\section{CONCLUSION}

Estimation of time since death has been a requisite in forensic investigation and it needs multiple techniques and methods so that suitable methodology can be applied in any situation accordingly. One such effort is to estimate postmortem interval through increase in concentration in CSF proteins which showed a linear rise with increasing time of death. Fluid like CSF is present in close cavity so chances of environmental and external factors are less. This can be helpful in forensic investigations to estimate postmortem interval as less technique is required, process is simple without any complications and the reagents required are easily available and less expensive. This can be a doorstep for further researches.

However, this technique is limited to $72 \mathrm{hrs}$ and time limit can be expended. Present research has been conducted in Forensic Department KEMU, Lahore and cases involved are only from those areas which come under the aforesaid department. Study can be broadened by using cases from rest of areas of Lahore even from others areas of Pakistan as well. 


\section{REFERENCES}

1. Morikawa K, Watanabe S. Time related change evaluation of the cerebrospinal fluid using postmortem CT. Legal med.2016; 22(1):30-5.

2. Kaszynski RH, Nishiumi S, Azuma T. et al. Postmortem interval estimation: A novel approach utilizing gas chromatography / mass spectrometrybased biochemical profiling. Anal Bioanal chem. 2016; 408(12): 3103-112.

3. Sobue S, Sakata K, et al. Characterization of gene expression profiling of mouse tissue obtained during the postmortem interval. Exp Mol Pathol. 2016; 100(3): 482-92.

4. Maile AE, Inoue CG, Barksadale LE, Carter DO. Toward a universal equation to estimate postmortem interval. Forensic Sci Int. 2017; 272(1): 150-53.

5. Sharma R, Garg RK, Gaur JR. Various methods for the estimation of postmortem interval from Calliphoridae: A review. Egyptian Journal of Forensic Sciences. 2015; 5(1): 1-12.

6. Johnnson HR, Trinidad DD, et al. A machine learning approach for using the postmortem skin microbiome to estimate the postmortem interval. Plos. Org. 2016; DOI.org/10.1371/journal. Pone 0167370 .

7. Yadav AB, Angadi PV, Kale AD, Yadav SK. Histological assessment of cellular changes in postmortem gingival specimens for estimation of time since death. J Forensic Odontostomatol. 2015; 33(1): 19-26.

8. Ding Y. et al. Estimation of postmortem interval by vitreous potassium evaluation with a novel fluorescence aptasensor. Sci. Rep. 2017; 7(1): 1868.

9. Stuart BH, Notter SJ. Et al. The formation of adipocere in model aquatic environments. Int J Legal Med. 2016; 130: 281-86.

10. Pittner S, Bugelli V, et al. The applicability of Forensic time since death estimation methods for buried bodies in advanced decomposition stages. Plos One. 2020; 15(12): 0243395.

11. Wescott DJ. Recent advances in forensic anthropology: decomposition research. For Sci Research. 2018; 3(1): 278-293.

12. Mathur A, Agarwal YK. An overview of methods used for estimation of time since death. Aust J Forensic sci.2011; 43(4): 275-85.

13. Bicker J, Alves G, Fortuna A et al. Blood-brain barrier models and their relevance for a successful development of CNS drug delivery systems: A review. European J Pharm \& biopharma. 2014; 87(3): 409-432.

14. Serlin Y, Shelef I, Knyazer B et al. Anatomy and physiology of the blood-brain barrier. Seminars in Cell \& Developmental biology. 2015; 38(1): 2-6.

15. Banerjee J, Shi Y, Azevedo HS. In vitro blood-brain barrier models for drug research: state -of-the-art and new perspectives on reconstituting these models on artificial basement membrane platforms. Drug Discovery Today. 2016; 21(9):1367-1386.

16. Donaldson AE, Lamont IL. Estimation of postmortem interval using biochemical markers. Aust J forensic sci. 2014; 46(1):8-26.

17. Cappella A, Gibelli D, Muccino E. et al. The comparative performance of PMI estimation in skeletal remains by three methods(C-14, luminol test and $\mathrm{OHI}$ ): analysis of 20 cases. Int $\mathrm{J}$ Legal Med. (2018); 132(4):1215-224.

18. Parmar AK, Menon SK. Estimation of postmortem interval through albumin in CSF by simple dye binding method. Science \& Justice. 2015 Dec 1; 55(6):388-93.

19. Morikawa K, Hyodoh H, Matoba K, Mizuo K, Okazaki S, Watanabe S. Time-related change evaluation of the cerebrospinal fluid using postmortem CT. Legal medicine. 2016 Sep 1;22:30-5

\section{The Authors:}

Dr. Arooj Farooq

Demonstrator,

Department of Forensic Medicine,

Nawaz Sharif Medical College, Gujrat.

Dr. Aatiqa Abbas

Demonstrator,

Department of Forensic Medicine,

King Edward Medical University, Lahore.

Prof. Arif Rasheed

Former Chairman and HOD,

Department of Forensic Medicine,

King Edward Medical University, Lahore.

\section{Corresponding Author:}

Dr. Arooj Farooq

Demonstrator,

Department of Forensic Medicine,

Nawaz Sharif Medical College, Gujrat.

Email: draroojsifat@gmail.com 